\title{
Narrative Structure and Narrative Development in Deaf Children
}

CHRISTIAN RATHMANN, Centre for Deaf Studies, University of Bristol, UK; WOLFGANG MANN, Deafness Cognition and Language Research Centre, UCL, UK; GARY MORGAN, Language and Communication Science, City University London, UK

\begin{abstract}
Researchers, the Deaf community, teachers of deaf children and speech and language therapists all share a concern about how to improve deaf children's written language skills. One part of literacy is story writing or narrative. A finding from a small number of studies is that children exposed to sign language from early childhood onwards achieve the highest level of bilingualism and become skilled readers and writers (Hoffmeister, 2000; Morgan, 2005). Potential contributing factors may include first language transfer, meta-linguistic awareness, cognitive readiness, motivation, parental interaction and emotional well-being. This paper reviews the first three contributing factors and outlines the theoretical case for bilingual narrative activities in deaf children. Copyright (C) 2007 John Wiley $\mathcal{E}$ Sons, Ltd.
\end{abstract}

Key words: literacy, metalinguistic awareness, bilinguism, sign language

\section{INTRODUCTION}

Research into deaf children's literacy development since Conrad (1979) does not point towards a big improvement in performance (Mayer, 2007). This is despite a growth in the awareness of the importance of bilingual education 
as a tool for helping deaf children access the school curriculum (Swanwick and Gregory, 2007). Although sign languages and written versions of spoken languages are now widely used side-by-side in many school classrooms throughout the USA and Europe, it is not always the case that deaf children have meta-linguistic awareness of how both types of languages overlap and differ.

Schools that adopt a sign bilingual framework ensure that both signed and spoken languages are used in the classroom, but due to lack of applied research and educational materials, there is still no clear picture of how to work on deaf children's bilingual comparative knowledge of sign and text systematically and efficiently. In this article, we suggest that bilingual education and the use of sign language particularly can provide a route to literacy, and examine how the understanding of narrative in a sign language can contribute to deaf children's meta-linguistic development and therefore literacy skills. We begin with a general definition of narrative and a summary of recent research into the structure of signed language narratives. Next, we provide a brief review of narrative development in British Sign Language (BSL) and English which is followed by a third section that focuses on the potential relationship between sign language proficiency and literacy skills. In the fourth section, we lay out some issues for sign language literacy development in deaf children including the argument that literacy, in terms of meta-linguistic awareness of sign language narrative, can feed into and strengthen written language understanding. We conclude the paper by outlining an idea for a bilingual narrative training project, which has the aim of promoting awareness of discourse structure in signed and written texts in teachers and deaf school children. In this proposed future study, we will explore the relationship between sign language knowledge and literacy development by focusing on the role of meta-linguistic awareness for the development of literacy skills within a narrative context. We expect to find that deaf learners with high meta-linguistic awareness of discourse structure and devices in BSL will be able to apply this knowledge across to their English literacy skills. Our main hypotheses are that meta-linguistic awareness of how signed narratives are constructed, how to encode shifts in perspective and describe reasons behind character motives can feed into the development of the same literacy skills in the written form. To test these hypotheses, we will investigate whether deaf children who take part in meta-linguistic training show significantly better literacy improvements than our control groups with no meta-linguistic training.

\section{Narrative discourse}

Narrative is a text composed in signed, written or spoken medium. Narrative is taken to be a particular use of language, and 'discourse' is a term used to describe a particular analytical level of language structure, involving the conjoining of several utterance strings across the sentence boundary. Narrative 
involves the building up of layers of information about characters, places and events. The production of a narrative involves the coordination of three cognitive domains:

(1) Linguistic devices are used within and across sentences and bigger discourse units including episodes and settings (Peterson and McCabe, 1990).

(2) Pragmatic abilities are central in narrative production and comprehension, including the awareness of a conversation partner or addressee's information needs (Hudson and Shapiro, 1991).

(3) Domain general cognitive abilities are involved in narrative such as working memory and information processing for the sequencing of large amounts of information (Eisenberg, 1985).

These three aspects are involved in narrative production and comprehension in signed, spoken or written texts. Signed narratives have a set of devices for conjoining sentences, as do spoken languages. Discourse structure in sign and English has episodes, scenes, plots and sub-plots. Pragmatic knowledge of a listener's needs is very similar to that required for a viewer of a signed narrative. Children's development of language related working memory and language processing is equally important for accessing information in texts as signed discourse.

Narrative structure in signed and spoken languages

Signed languages have evolved similar and different surface devices to spoken languages for constructing a connected narrative and strategies for achieving coherence and cohesion across sentences. When narrating, signers build up layers of information about characters, places and events. As in English narratives, signers first establish reference, in the form of noun phrases, for example, $\mathrm{BOY}, \mathrm{FROG}$ or DOG. One strategy which is commonly used is establishing a location for the referent in the signing space (Emmorey and Lillo-Martin, 1995). When a character's subsequent actions during the narrative are related, signers often use constructed actions and dialogues (Roy, 1989; Liddell and Metzger, 1998; Liddell, 2003) from a shifted first person perspective, for example, BOY (shift to boy's perspective) LOOK (with a worried face) (boy says) FROG WHERE? Direct discourse and dialogue are also common in English creative narratives. Without written punctuation, narrators use eye-gaze shifts to organise and structure signed texts (Bahan and Supalla, 1995; Gee and Kegl, 1983; Roy, 1989).

A different set of devices in signed narratives are termed classifier constructions. Expressing details of the movement of an entity through a narrative scene is often achieved by the selection of an appropriate classifier in the form of a handshape, which may represent a person, small animal or vehicle, etc. The classifier gets coupled with a specified movement or location, for example, 
BOY SEARCH-FOR (shift to boy's perspective) LOOK-AROUND (classifier) PERSON-STAND-ON-ROCK.

While the particular forms used by signers differ to those used in written texts (handshapes, eye-gaze shifts, space, etc), their function as literacy markers are very similar. As the last example illustrates, linguistic devices in sign languages describe events from different perspectives. Consider this written English excerpt:

Kreacher stopped in his tracks. Harry could just make out the back of his bald head through the forest of chairs before them. 'Master does not tell poor Kreacher where he is going,' said the elf quietly (Rowling, 2003, p. 653).

Being able to switch between different character's perspectives makes a narrative interesting and rich. As described above, perspective shifts in signed narratives are very common. Children's ability to record perspective shifts in their narratives develops with age, as they become increasingly able to handle different points of views (Slobin, 1996). Deaf children's knowledge of how this aspect of narrative in signed language or written text functions can feed into literacy development.

\section{NARRATIVE DEVELOPMENT IN ENGLISH AND BSL}

There are many parallel findings for what develops, at what time and with what errors from research into narrative development in signed and spoken languages. Hearing children exposed to English even as young as 2 years old begin to talk about past events. These proto-narratives are heavily scaffolded by an adult. By 3-4 years children can talk about one or more events and begin to use structural components of narrative. These include the setting of information ('where' but not 'who'), events, complications and endings/outcomes. At this age they are inconsistent in the use of cohesion and sequence (they focus on what interests them, rather than story chronology). Sentence chaining, using 'and then' is common and despite limited resources children are very expressive. By 5-7 years, narratives include where, when and who information and children show that they can understand basic emotions and intentions. Children begin to structure stories around a goal, logical progression of events with inclusion of sub-plots and understanding of time frames. At 8-10 years, children use most structural components correctly and importantly demonstrate they understand how to tell a story to another person. Their stories indicate they understand more complex emotions (e.g. jealousy). At this age they still show inconsistent reference between events and characters (anaphora). After 10 years, stories are more complex, detailed and structurally coherent. Children use a range of linking devices, for example, 'and', 'so' and 'when', and also demonstrate more effort to engage the listener's attention and adapt to different audiences.

There are far fewer studies of narrative development in deaf signing children, and these are based on small numbers. Morgan (2002) and Morgan and 
Woll (2003) investigated BSL narratives and proposed some general milestones. Deaf 3 year olds' use of reference is unclear and they are unable to use sign space to clarify characters or actions. Characters are often introduced into the story without clear indication of who they are. Areas of sign space are not divided up for different characters appropriately leading to interlocutor misunderstandings. By $4-6$ years, classifiers begin to be used within sentences, but not referentially within sign space across sentences, for example, child uses the same location for many different referents. At this age, there is a lack of clarity when changing character through reference shift. Children may focus on one character only when there are several in the story. Both deaf and hearing children at this age have difficulty introducing sub-plot complications, with their own time frames, into the overarching plot.

Between 7 and 10 years, children's ability to mark reference in stories improves, but they still show difficulties maintaining these references across long stretches of discourse. Again, a common problem between hearing and deaf children, at this stage in narrative development, is that in events where more than one character is involved children still describe different characters' actions sequentially rather than switching between overlapped events. Across signed and spoken languages full mastery of narrative devices is timed to occur through 11-13 years (Morgan, 2002; Morgan and Woll, 2003).

Evidence of similar developmental patterns of deaf children in other countries includes research on American Sign Language (ASL) by Anthony (2002), French Sign Language (LSF) by Niederberger (2004) and Canadian Sign Language (LSQ) by Vercaingne-Menard et al. (2001), all of which report a similar lack of verb modulation and spatial referents, as well as the use of simple classifier constructions rather than classifiers embedded in complex structures. A recent study on narrative development in German Sign Language (DGS) and written German in bilingually educated deaf children (Pust and Weinmeister, 2006) reveals a temporal lag in students' acquisition of written language. In addition, the data show mixing rates between the two languages at the level of word order and in the expression of spatial references. These mixing rates at the syntactic and morphological levels decrease as learners' progress in their DGS development.

Fortunately, further research into deaf children's narrative development has been made possible due to the recent development of a new standardised assessment. The BSL Production Test (Herman et al., 2004) is designed for children aged 4-11 years and is based on analysis of an elicited narrative, which is coded for narrative structure, content and features of BSL grammar. The test allows for comparison of scores between each of these areas. This test is similar to the Bus story assessment used in spoken language research (Renfrew, 1997). Features of narrative skills include scene setting, chronological ordering of events, description of plot complications and conclusions. For deaf children, successful understanding of these features in BSL can serve as stepping stones to acquiring another language (e.g. English). 


\section{THE CORRELATION BETWEEN KNOWLEDGE OF SIGNED LANGUAGE AND LITERACY ABILITIES: LANGUAGE TRANSFER}

Because of the clear parallels between language development in deaf and hearing children, as well as the clear overlap in cognitive and pragmatic abilities required in good story telling in both types of languages, researchers have argued that language and cognitive transfer may be two of the driving forces behind the 'good signers make good readers' phenomenon.

Several American researchers have suggested that there is a significant correlation between linguistic competency in signed languages and reading competence. The simple argument being that ASL fluency provides the child with a linguistic foundation that enables development of literacy skills in English (Strong and Prinz, 1997; Singleton et al., 1998; Hoffmeister, 2000; Chamberlain and Mayberry, 2000; Padden and Ramsey, 2000).

Hoffmeister (2000) presented significant correlations between performance on reading comprehension (Stanford Achievement Test, SAT) and performance on specific ASL linguistic tests, for deaf children aged 8-15, with age partialled out. Those whose ASL proficiency was high displayed a good correlation with performance in the SAT reading comprehension. Strong and Prinz (1997) also argued that ASL fluency facilitates reading development in English. Young deaf children with deaf mothers had better reading skills than deaf children in hearing families who did not sign. The gap closed as both sets of deaf children became older and the non-native group began to acquire ASL. Padden and Ramsey (2000) also attested the correlation between ASL competency and reading skills. Young Deaf signers whose reading skills were more able to write down fingerspelled words, as well as to match initialised (e.g. sign incorporates some finger spelling) signs with corresponding words written in English. Research with Deaf children who access language late has documented difficulties with the development of narratives in any form of language (Gray and Hosie, 1996).

\section{SIGN LANGUAGE LITERACY STUDY FOR DEAF CHILDREN}

Meta-linguistic awareness is broadly defined as conscious knowledge of the formal aspects of a language, for example, how to mark perspective shifts. The Bialystok and Ryan (1985) information-processing model explains what the relationship between meta-linguistic awareness and second language proficiency is. While meta-linguistic awareness is unnecessary for first language development, it becomes crucial for any individual's development of a non-native second language (as is the case for deaf children's development of English). The model posits that successful language learning is influenced by the development of analysed linguistic knowledge (a linguistic understanding of the devices in one's languages) and control. The control component covers three functions: 
(1) the selection of the correct linguistic items for a particular function;

(2) the coordination of these items;

(3) and the extent to which selection and coordination can be carried out automatically.

Bialystok and Ryan (1985) argue that making second-language learners aware of linguistic forms at their disposal and how to control these forms makes learners aware of implicit knowledge and in turn makes knowledge explicit.

We continue within this framework to think about deaf children becoming literate in both signed and spoken languages. Literacy is the ability to use language in different modes efficiently and adequately. The two modes in question here are sign languages (e.g. BSL) and the ability to sign to and understand an interlocutor (i.e. someone taking part in a conversation) or more interlocutors adequately, and produce and understand signed texts (vlogs, VHS, etc). The second mode is spoken languages (e.g. English) and the ability to: (a) speak to and understand an interlocutor or more interlocutors adequately, and (b) produce and understand written texts adequately. Literacy in deaf children is dependent on the development of improved educational programmes, teaching strategies and assessment tools. Literacy for deaf children leads to enhancements in the quality of life of deaf signers in terms of the 'Global Information Society' and of access to texts in various formats (e.g. blogs and vlogs).

In recent years, there has been a growing interest by researchers and sign language users in identifying and describing linguistic properties and discourse conventions in academic or educational settings. One of the main reasons for this interest is the study of deaf learners' meta-linguistic awareness of how connected texts, such as narratives, work. This awareness marks an important first step in learners' ability to access and produce academic texts. Consequently, the systematic study of narrative structure and narrative development can help us understand academic register in BSL and other signed languages and, as a result, the notion of literacy in BSL and other signed languages.

To summarise the above sections, we have identified that sign and spoken languages have overlapping linguistic organisation at the discourse level. There exist strong parallels in children's development of discourse knowledge in signed and spoken languages. Furthermore, there exists a significant correlation between deaf children's signing skills and literacy development. Finally, there is a recognised importance attributed to meta-linguistic awareness for second language acquisition.

\section{OUTLINE FOR FUTURE RESEARCH}

In this paper, we have pointed out the significance of deaf learners' metalinguistic awareness of narrative structure and how the systematic study of these structures and narrative development can help researchers to understand the notion of literacy in BSL and other signed languages. In this final section, 
we lay out our plans for a new literacy intervention study based on the work reviewed above.

The study contains three phases: in the first period we will analyse several adult signed and written narratives based on the Frog, Where Are You? story (Mayer, 1969) in BSL and English. We will pay special attention to the use of nominal, temporal and spatial reference, the use of viewpoint including constructed action, dialogue and narrator's perspective, the use of prosody and written punctuation, the use of other grammatical elements including classifier constructions, prepositions in English, and the use of signing space and syntactic devices in English.

During the same period researchers will investigate and document the developmental stages of narrative competency in signed and written Frog stories in deaf children. The study includes deaf native signers (who were born to Deaf parent/s and acquired sign language from birth), early signers (who were born to hearing parents and were exposed to sign language between ages 1 and 3 ) and late signers (who were born to hearing parents and were exposed to sign language after age 4) in three age groups (6-9, 10-13 and 14-17). Cross-sectional analyses will be conducted, which will seek correlations among three variables: (i) age of exposure to sign language (native, early and late signers), (ii) current age group of the subject (6-9, 10-13 and 14-17), and (iii) narrative abilities in signed and written languages.

In the second phase, we will focus on the development of instructional materials. This will take place in close collaboration with deaf and hearing teachers of the deaf. Our work on typical and atypical narrative development with different age groups, carried out in phase one, will inform our development of appropriate materials for native and non-native learners. One possibility will be materials that focus on 'Story grammar' (Beck and McKeown, 1981). This approach is a type of teaching strategy for enhancing the meta-linguistic awareness of structure in both signed and written languages.

In collaboration with the teachers, we will develop a number of different literacy activities that focus on bridges between both types of language. During this period we will also work with teachers to examine language use in the classroom and assess teaching practices, as well as evaluate our bilingual narrative materials in educational settings. For these purposes, we will develop a number of assessment tools needed to assure an appropriate measurement of the outcomes. We anticipate that results on the usability of instructional materials and teaching effectiveness will be available at the end of the second phase.

In the final phase we will carry out a delayed intervention study in the classroom, using the teaching practices developed in partnership with teachers of the deaf. The control groups will have traditional literacy training, but will only receive the new meta-linguistic training six months after our main experimental groups. Our hypothesis is that the children who take part in metalinguistic training will make significantly better literacy improvements than 
the control groups. Based on the results of this study, our long-term goals are to provide schools with materials to facilitate teachers' approaches to teach deaf students the comparative discourse patterns in BSL and English.

We agree that a crucial aspect of early literacy is 'breaking the code' and phonological awareness in English is an important skill for doing this. Once children are reading simple sentences however, how do we get them interested in exploring and constructing complex narratives? How can deaf children develop the social-cognitive abilities necessary to understand typical multicharacter novels? We think that meta-linguistic awareness of how signed narratives are constructed, how to encode shifts in perspective and character motives can feed into the development of the same literacy skills in the written form.

\section{REFERENCES}

Anthony M. The role of American Sign Language and "conceptual wholes" in facilitating language, cognition, and literacy. Unpublished doctoral dissertation, University of California, Berkeley, CA, 2002.

Bahan B and Supalla S (1995). Line segmentation and narrative structure: A study of eye gaze behavior in American Sign Language. In: Emmorey K and Reilly J (Eds) Language, Gesture and Space. Hillsdale, NJ: Lawrence Erlbaum Associates, pp. 171-191.

Beck IL and McKoewn, GM. Developing questions that promote comprehension: The storymap. Language Arts 1981; 58: 913-918.

Bialystok E and Ryan EB. A metacognitive framework for the development of first and second language skills. In: Forrest-Pressley DL, Mackinnon GE, and Waller TG (Eds) Metacognition, cognition, and human performance. New York: Academic Press, 1985: $207-252$.

Chamberlain C and Mayberry R. Theorizing About the Relation Between American Sign Language and Reading. In: Chamberlain C, Morford J, and Mayberry R (Eds) Language Acquisition by Eye. Mahwah NJ: Lawrence Erlbaum Associates, 2000: 222-259.

Conrad R (1979). The Deaf School Child: Language and Cognitive Function. London: Harper \& Row.

Eisenberg, AR. Learning to describe past experiences in conversation. Discourse Processes 8, 1985: 177-204.

Emmorey K and Lillo-Martin D. Processing Spatial Anaphora: Referent Reactivation with Overt and Null Pronouns in American Sign Language. Language and Cognitive Processes 10, 1995: 631-664.

Gee J and Kegl J. Narrative/story structure, pausing and American Sign Language. Discourse Processes 6, 1983: 243-258.

Gray CD and Hosie JA. Deafness, Story Understanding, and Theory of Mind, Journal of Deaf Studies and Deaf Education 1: 4, 1996: 217-233.

Herman R, Grove N, Holmes S, Morgan G, Sutherland H, and Woll B. Assessing British Sign Language Development: Production Test (Narrative skills). London: City University, 2004.

Hoffmeister R. A Piece of the Puzzle: ASL and Reading Comprehension in Deaf Children. In: Chamberlain C, Morford J, and Mayberry R (Eds) Language Acquisition by Eye, Mahwah, NJ: Lawrence Erlbaum Associates, 2000: 143-164.

Hudson JA and Shapiro CR. From knowing to telling: the development of children's scripts, stories and personal narratives. In: McCabe A and Peterson C (Eds) Developing narrative structure. Hillsdale, NJ: Lawrence Erlbaum Associates, 1991: 89-136. 
Liddell S. Grammar, gesture, and meaning in American Sign Language. Cambridge, UK: Cambridge University Press, 2003.

Liddell S and Metzger M. Gesture in Sign Language Discourse. Journal of Pragmatics 30, 1998: 657-697.

Mayer C. What really matters in the early literacy development of deaf children. Journal of Deaf Studies and Deaf Education, advance access published on 12 June 2007. DOI:10.1093/ deafed/enm020, 2007, 121; 411-431.

Mayer M. Frog, Where Are You? New York: Dial Press, 1969.

Morgan G. The encoding of simultaneity in children's BSL narratives. Journal of Sign Language and Linguistics 5:2, 2002: 127-161.

Morgan G and Woll B. The development of reference switching encoded through body classifiers in British Sign Language. In: Emmorey K (Ed.) Perspectives on classifier constructions in sign languages. Mahwah, NJ: Lawrence Erlbaum Associates, 2003: 297-310.

Niederberger N. Capacites langagieres en langue des signes francaise et en francais ecrit chez l'enfant sourd bilingue: Quelles relations? Unpublished doctoral dissertation, University of Geneva, 2004.

Padden C and Ramsey C. American Sign Language and Reading Ability in Deaf Children. In: Chamberlain C, Morford J, and Mayberry R (Eds) Language Acquisition by Eye. Lawrence Erlbaum Associates, 2000: 165-189. Mahwah, NJ.

Peterson $\mathrm{C}$ and McCabe A. Linking children's connective use and narrative microstructure. In: McCabe A and Peterson C (Eds) Developing narrative structure. Hillsdale, NJ: Erlbaum, 1990.

Pust CP and Weinmeister K (2006). Narrative development in German Sign Language and written language: developmental asynchronies and language contact. In: Quadros RM (Ed.) TISLR 9 Congreso International de Aspectos Teóricos das Pesquisas nas Linguas de Sinais. Florianópolis, SC: Lagoa Editora, pp. 165-177.

Renfrew CE. Bus Story Test. Derbyshire, UK: Winslow Press, 1997.

Rowling JK. Harry Potter and the order of the Phoenix. London, UK: Bloomsbury, 2003.

Roy C. Features of discourse in an American Sign Language lecture. In: Lucas C (Ed.) The Sociolinguistics of the Deaf communitiy. San Diego, CA: Academic Press, 1989: 231-252.

Singleton J, Supalla S, Litchfield S, and Schley S. From sign to word: considering modality constraints in ASL/English bilingual education. Topics in Language Disorders 18, 1998: $16-29$.

Slobin D. From 'thought to language' to 'thinking for speaking'. In: Gumperz J and Levinson S (Eds) Rethinking linguistic relativity. Studies in the social and cultural foundations of Language. Vol. 17. Cambridge, MA: Cambridge University Press, 1996: 70-96

Strong M and Prinz PM. A Study of the Relationship Between American Sign Language and English Literacy. Journal of Deaf Studies and Deaf Education 2:1, 1997: 37-46.

Swanwick R and Gregory S. Sign Bilingual Education: Policy and Practice. Forest Books Gloucester, UK, 2007.

Vercaingne-Menard A, Godard L, and Labelle, M. The emergence of narrative discourse in two young deaf children. In: V. Dively (Ed.), Sign Languages: Discoveries from International Research. Washington, DC: Gallaudet University Press, 2001: 120-132.

Address correspondence to: Gary Morgan, LCS, City University London, Northampton Square, London EC1VOHB, UK. (E-mail: g.morgan@city.ac.uk) 